\title{
O processo de planejamento para o desenvolvimento regional e suas interfaces com a consulta popular no COREDE Alto Jacuí: uma reflexão para o período de 2009 a 2012.
}

\author{
The planning process for regional development and its interfaces with the popular consultation in COREDE \\ Alto Jacuí: a reflection for the period 2009/2012.
}

\section{José Carlos Severo Corrêa}

\author{
Universidade Federal do Pampa - UNIPAMPA - Bagé - Rio Grande do Sul - Brasil
}

\begin{abstract}
Resumo: O presente texto é resultado da sistematização de três outros trabalhos realizados junto ao Conselho de Desenvolvimento Regional (Corede) Alto Jacuí entre os anos de 2009 e 2012. Os trabalhos em questão abordaram noções de desenvolvimento por parte da Assembleia Regional do Corede, o processo de planejamento regional e por fim as discussões feitas diante da Consulta Popular. Assim sendo, o objetivo do trabalho foi evidenciar a forma como as questões relacionadas ao desenvolvimento regional e a participação cidadã são abordadas no âmbito do Corede Alto Jacuí durante o período entre 2009 e 2012. Para tanto, buscouse analisar as interfaces existentes entre a noção de desenvolvimento estabelecida pela Assembleia Regional com as prioridades apontadas no Plano Estratégico e as demandas aprovadas pela população do Corede Alto Jacuí na Consulta Popular. Por intermédio de pesquisa documental, entrevistas e questionários, no que tange a cada um dos aspectos correlacionados, identifica-se públicos, situações e formas de manifestações distintas, embora não excludentes entre si, inclusive no instrumento de coleta dos dados. Por fim, conclui-se que no âmbito do Corede Alto Jacuí há ainda um longo caminho a ser percorrido quando se discute o desenvolvimento regional, o que denota ser este um processo dialético em construção, consequentemente inacabado e em permanente transformação.
\end{abstract}

Palavras-chave: Planejamento Regional. Participação Cidadã. Desenvolvimento Regional.

Abstract: This paper is the result of systematization of three other works carried out by the Regional Development Council (Corede) Alto Jacuí between the years 2009 and 2012 the works in question have addressed notions of development by the Regional Assembly of Corede, the process of regional and finally the discussions made on the Popular Consultation planning. Therefore, the aim of this study was to demonstrate how issues related to regional development and citizen participation are covered in the Corede Alto Jacuí during the period between 2009 and 2012. Therefore, it sought to analyze the interfaces between the development concept established by the Regional Council with the priorities identified in the Strategic Plan and the demands approved by the Corede Alto Jacuí population in the popular consultation. Through desk research, interviews and questionnaires, with respect to each of the related aspects identifies public, situations and forms of distinct but not exclusive to each other demonstrations, including data collection instrument. Finally, it is concluded that under the Corede Alto Jacuí there is still a long way to go when discussing regional development, which shows that this is a dialectical process in construction, unfinished and therefore constantly changing.

Keywords: Regional Planning. Citizen Participation. Regional Development. 


\section{Introdução}

O Rio Grande do Sul vivencia desde 1991 uma experiência de descentralização e regionalização nos seus processos de planejamento e orçamentação, a partir da criação dos Conselhos Regionais de Desenvolvimento (Coredes). A Lei 10283/94 traz como objetivo principal desses conselhos, a articulação pela promoção do desenvolvimento regional, com atribuições complementares de elaborar planos de desenvolvimento regional e manter espaço permanente de participação democrática, entre outras. (RIO GRANDE DO SUL, 1994)

Fruto da evolução e amadurecimento dessa experiência, em 1998 foi estabelecido por parte do Governo do Estado um processo de consulta à população, a qual delibera sobre a aplicação de um percentual do orçamento anual. Esse processo coordenado em conjunto com os Coredes vem sendo aperfeiçoado ao longo do tempo.

Em consonância com a legislação que os regulamenta, os Coredes passaram a pleitear e articular a viabilização de um processo de elaboração dos planos regionais de desenvolvimento como forma de direcionar a discussão nas regiões na busca de seus objetivos. Poucos Coredes conseguiram elaborar seus planos de desenvolvimento, em função da falta de recursos para custear o processo de planejamento. De acordo com Siedenberg; Saad; Senger (2004), apenas oito entre 22 Coredes possuíam documento formal de planejamento. Em 2009 o estudo foi replicado e mesmo com o número de Coredes tendo aumentado para 28, apenas os mesmos oito continham tal documento e reconheciam a necessidade de atualização de tais planos (SIEDENBERG, 2010). Dessa forma, no ano de 2009 - governo do Estado financiou a elaboração dos planos regionais de desenvolvimento que, pela trajetória histórica, ao menos em tese, deveriam embasar a carteira de projetos para a discussão em torno do desenvolvimento regional.

No entanto, a existência de tais planos ainda deixa uma lacuna, que se refere à falta de estrutura dos diferentes Coredes no gerenciamento dos seus planos de forma adequada. Disso vislumbra-se que a Consulta Popular possa ser um meio de obtenção de fontes de financiamento da execução do plano, minimizando assim a debilidade decorrente da falta de um mecanismo mais estruturado de gestão do mesmo. Com base nessa perspectiva é que se busca com o presente trabalho fazer uma reflexão a respeito das temáticas que envolvem a atuação dos Coredes. Conforme preconiza a lei de criação desses conselhos e inclusive em sua própria denominação, envolve o desenvolvimento regional, e de acordo com o já apresentado nos parágrafos anteriores, são interfaces importantes: a participação e o planejamento.

O presente texto é resultado da sistematização de três outros trabalhos realizados junto ao Corede Alto Jacuí entre os anos de 2009 e 2012. Trabalhos esses que são fruto da combinação do exercício profissional do autor, seja como professor, seja na sua atuação junto à diretoria executiva do referido conselho. Obviamente que a condição de pesquisador também é contemplada, na medida em que alguém interessado em compreender melhor os fatos inerentes ao seu universo de atuação acaba se inserindo com mais profundidade na temática relacionada ao desenvolvimento regional de forma geral e à participação cidadã de forma particular, contemplando, inclusive, a tríade indissociável do trabalho universitário, do ensino, da pesquisa e da extensão.

A base da reflexão aqui proposta remete às discussões relacionadas ao processo de planejamento para 0 desenvolvimento regional (CORRÊA et al, 2010), e a dois trabalhos acadêmicos de natureza empírica, cujo ambiente de estudo é a região do Alto Jacuí no que diz respeito aos temas já mencionados, o desenvolvimento regional (LIMA, 2011; CORRÊA, 2013) e a participação cidadã (CORRÊA, 2013). Mesmo os trabalhos mencionados sendo empíricos, é necessário fazer uma reflexão teórico-conceitual básica, que especificamente será feita a partir de quatro grandes referenciais: i) desenvolvimento regional; ii) planejamento para o 
desenvolvimento; iii) participação; e iv) instituições. Importante salientar que nessa recuperação teórica não há a pretensão de trazer o estado da arte e tampouco de esgotar a discussão, tratando-se apenas de pontuar a base teórica que determina a reflexão do autor e consequentemente pauta sua discussão.

Com relação aos textos anteriormente mencionados, cada um com finalidade distinta e, consequentemente, graus de profundidade também distintos, tratam-se de trabalhos de extensão no primeiro caso, o processo de planejamento, e de pesquisa e ensino nos outros dois casos, desenvolvimento regional e a participação cidadã. A ideia geral foi de evidenciar a forma como as questões relacionadas ao desenvolvimento regional e a participação cidadã são abordadas no Corede Alto Jacuí. Especialmente porque no período relacionado abriu-se a possibilidade de tornar a discussão mais aberta e direta em função da concomitância de dois eventos, o processo de planejamento, realizado em 2009 e 2010, e a consulta popular, que é feita no Rio Grande do Sul desde 1998. Mas o fato é que os três trabalhos mencionados, embora realizados em momentos diferentes com objetivos distintos e graus de complexidade igualmente diversos, lidos em conjunto possibilitam uma reflexão mais articulada das temáticas, inclusive abrindo possibilidades para novos estudos em função das eventuais lacunas identificadas na proposta ora apresentada.

Assim sendo, o presente trabalho tem como objetivo analisar as interfaces existentes entre a noção de desenvolvimento estabelecida pela Assembleia Regional com as prioridades apontadas no planejamento e as demandas aprovadas pela população da região na Consulta Popular durante o período entre 2009 e 2012. Importante salientar que, no que tange a cada um dos aspectos ora correlacionados, identifica-se públicos, situações e formas de manifestações distintas, embora não excludentes entre si, inclusive no instrumento de coleta dos dados.

Com a expectativa de satisfazer a proposição, o presente trabalho está organizado em quatro seções, além desta introdução. Na segunda seção é feita a já mencionada reflexão da base teórica de sustentação da discussão, que reafirma-se, não tem a pretensão de esgotá-la, subdividida nos quatro grande elementos conceituais já mencionados. $\mathrm{Na}$ terceira seção são apresentados os elementos constitutivos metodológicos que, em síntese, apresenta a base analítica a partir de uma abordagem dialética bem como a apresentação dos instrumentos de coleta e técnicas de análise. Na quarta seção é feita a discussão contextualizada e apresentação dos resultados para culminar na seção das considerações finais que evidenciam ser este um processo em construção e consequentemente inacabado e em permanente transformação.

\section{A compreensão sobre desenvolvimento regional, planejamento, participação e instituições}

Conforme já mencionado, a presente seção tem o propósito de discutir brevemente os conceitos que fundamentam a análise dos dados a partir da proposta metodológica, a saber: desenvolvimento, planejamento, participação e instituições.

De acordo com Lopes (2008), o desenvolvimento pode ser considerado um dos conceitos mais produtivos e polêmicos nas Ciências Sociais e por muito tempo a Economia ocupou um papel de relevo em sua definição. Somente a partir da década de 1930, outras disciplinas passaram a contribuir permitindo a renovação do conceito e das estratégias desenvolvimentistas.

Segundo Nalle Junior (2006), a ciência econômica concebeu o desenvolvimento de forma simplista, se tratando de apenas melhorar os indicadores econômicos. Ao longo do tempo, o desenvolvimento assume também uma dimensão subnacional, como fica claro na afirmação de Lima e Simões (2009), de que o mesmo ocorre de forma desigual e, uma vez iniciado em determinados pontos, possui a característica de fortalecer as regiões mais dinâmicas, e que se configura em aspectos intra e inter-relacionados às mesmas. 
Segundo Costa e Cunha (2002), a partir do final da década de 1970 surgiu uma nova visão para o conceito de desenvolvimento, contemplando não apenas o crescimento da produção nacional, mas também a partir de avanços na qualidade de vida, na equidade, na democratização, na participação cidadã e na proteção ao ambiente.

$\mathrm{Na}$ perspectiva subnacional, Ramos e Marino (2004) destacam que o desenvolvimento regional remete a uma dualidade: de um lado, o processo global corporativo, incidindo como fator exógeno nas comunidades e, de outro, a reação das mesmas, em termos socioambientais, que emana endogenamente. Condicionam o processo de desenvolvimento, as configurações históricas regionais, sociais e físiconaturais específicas, e também sua dinâmica, sintetizando, portanto, uma combinação de assimilação/reação.

Também nessa perspectiva, Sen (2000) desconstroi a lógica até então predominante de raciocínio, ao ponderar que o desenvolvimento pode ser visto como um processo de expansão das liberdades reais que as pessoas desfrutam, não negando a importância dos aspectos ditos econômicos, mas esses como insuficientes para tanto. Tais liberdades dependem também das disposições sociais, acesso aos serviços de educação e saúde, e dos direitos civis, a possibilidade de participação das discussões públicas.

A argumentação remete ao enfrentamento da condição inicial de uma determinada região, para que no futuro, a mesma melhore sua situação em comparação ao momento anterior. Sendo assim, fica evidente que o desenvolvimento está relacionado a uma condição de planejamento do mesmo. Nos dizeres de Oliveira e Lima (2003, p. 31): "pensar em desenvolvimento regional é, antes de qualquer coisa, pensar na participação da sociedade local no planejamento contínuo da ocupação do espaço e na distribuição dos frutos do processo de crescimento".

Quer queiramos ou não, estratégias bemsucedidas de desenvolvimento regional estão, normalmente, associadas, nos tempos recentes, a vigorosas estratégias (re) estruturantes de desenvolvimento regional (vontades coletivas regionais), executadas pelas organizações e instituições das comunidades regionais, ou seja, estratégias formuladas e executadas por sujeitos coletivos regionais. (BECKER, 2003, p.61-2)

De acordo com os autores, o avanço no desenvolvimento de uma região está condicionado a um processo de planejamento do mesmo e que deve ser visto como um processo participativo, desenvolvido para o alcance de uma situação desejada. A participação da comunidade regional visa assegurar maior eficiência ao processo na medida em que estimula a produção de ideias, agindo como um impulsionador de mudanças locais, além de gerar um maior comprometimento da mesma com os resultados do processo.

Prevalece, neste caso, o ponderado por Siedenberg e Allebrandt (2010): o entendimento de que planejamento não é só técnico, mas também político, pois abrange o encaminhamento de soluções técnicas para o âmbito da decisão política, bem como a criação de atitudes políticas de aceitação para as decisões técnicas de planejamento.

Segundo Buarque (1999, p. 35), os "métodos e técnicas devem ser adaptados e ajustados às concepções contemporâneas de planejamento e de desenvolvimento, (...) Isto significa: visão de longo prazo, abordagem sistêmica, tratamento multidisciplinar, negociação política e participação social".

Conforme Siedenberg e Allebrandt (2010, p. 32) o planejamento é uma representação da sociedade exercendo o poder sobre seu futuro por meio de iniciativas que definam seu destino, negando a resignação. Os autores corroboram Becker (2000), que sustenta a necessidade de se encontrar alternativas à democracia representativa de tal forma que se a mesma se torne uma democracia mais "subversiva" ou participante, com o poder de baixo para cima. No caso específico, está se falando de planejamento público aplicado em esfera regional e que por definição prévia deve envolver a participação da cidadania no processo.

Ainda, de acordo com Ugarte (2004, p.93), a argumentação de que a participação é um ingrediente 
fundamental das formas democráticas de governo é quase que óbvia, mas há que se esclarecer algumas questões. "De que tipo de participação estamos falando? Participação em quê? Para quê? Como? Além disso, entre quem?" A resposta a essas questões determinam a forma de governo de uma comunidade política, dependendo de como isso é expressado.

Conforme Teixeira (2002), nessas formas diferenciadas de expressão e ação coletivas, com ou sem conteúdo político explícito a depender dos seus objetivos e contextos, é importante que se considere o elemento político na relação social, mesmo quando se pretende construir uma identidade política negando o Estado na busca de autoafirmação coletiva e autogoverno:

\begin{abstract}
tal complexidade não pode ser reduzida a um mero ato eleitoral, episódico, individual, atomizado, mesmo que possa ter efeito aparentemente decisório. Processo contraditório envolve uma relação multifacetada de poder entre atores diferenciados por suas identidades, interesses e valores, os quais expressam sob várias formas, conforme a capacidade daqueles e as condições objetivas do regime político.

Entretanto, é preciso delimitar o conceito de participação e, para isso, é fundamental considerar o poder político, que não se confunde com autoridade ou Estado, mas supõe uma relação em que atores, com os recursos disponíveis nos espaços públicos, fazem valer seus interesses, aspirações e valores, construindo suas identidades, afirmando-se como sujeitos de direitos e obrigações (TEIXEIRA, 2002, p. 26).
\end{abstract}

A participação pode ser dividida entre orientada para a decisão e orientada para expressão. A primeira é caracterizada pela intervenção de forma organizada, não episódica, pelos atores da sociedade civil no processo decisório; já a segunda, de caráter mais simbólico e voltado para a expressão, caracterizada pela marcação da presença na cena política, mesmo que eventualmente possa ter impacto ou influência no processo decisório (TEIXEIRA, 2002).

Segundo Conceição e Nuñez (2007), a escala regional propicia e viabiliza preponderantemente a participação popular, dado que assegura uma maior transversalidade das políticas públicas e também pelo fato de ancorar as instituições e lideranças locais, o que possibilita a harmonização das diferentes formas de articulação na região ou território. Esse tipo de comportamento nada mais é do que a expressão de relações institucionais, o caso em pauta, Coredes e Governo, encontrando então, explicação no neoinstitucionalismo.

Lecours (2002) apresenta as três vertentes do neoinstitucionalismo: o histórico, o da escolha racional e o sociológico. No primeiro caso, a trajetória histórica e o contexto de uma sociedade explica os fenômenos, já no segundo, são levadas em consideração as decisões lógicas que são tomadas em função da busca pelo ganho individual. Já o terceiro caso está mais relacionado às conexões entre a sociedade e as instituições pelo sentido que estas últimas adquirem e difundem, colocando ênfase no aspecto cognitivo acima do contingencial.

neo-institucionalismo sociológico
conceptualiza as instituições como a
formalização de práticas culturais. (...)
Segundo esta abordagem, as instituições são
construções sociais. Elas são a imagem das
sociedades em que estão situadas. Em outros
termos, as instituições são reflexo das
percepções coletivas comuns e sua criação
corresponde à rotinização das relações
sociais. As instituições, pouco importa sua
natureza exata, são então compatíveis com a
sociedade. (LECOURS, 2002, p.11)

As ponderações feitas por Lecours bem sintetizam a reflexão proposta por este trabalho, pois a compreensão de que as instituições sejam fruto da formação histórica de uma sociedade é o que tem sido observado na trajetória corediana no Rio Grande do Sul. Tal trajetória tem origem em uma política pública configurada como de Estado, que embora sofra alguns percalços, avança com uma característica principal: a unidade sem padronização. Os Coredes avançam coletivamente, mas, na particularidade, são distintos entre si, tanto no nível de articulação e interação com suas comunidades, quanto no seu modo operacional.

A conexão conceitual aqui apresentada remete justamente a essa condição verificada ao longo da trajetória dos Coredes, desde sua criação, em 1991. O objetivo desses conselhos traz em sua gênese a 
questão da participação da sociedade civil na descentralização das decisões do governo. Esse objetivo se evidencia a partir de um processo de planejamento que é fortemente influenciado pelas questões institucionais, cujo resultado se traduz (ou deveria se traduzir) em desenvolvimento regional (melhoria das condições de vida da população).

Considerando que a ação dos envolvidos é influenciada pelas conexões do meio em que vivem, tanto em sua trajetória histórica quanto às circunstâncias momentâneas, esse é um comportamento explicado pelo neoinstitucionalismo sociológico. Portanto, esse o ponto central da discussão que se pretende estabelecer no presente trabalho, refletindo em torno das contradições contidas nessas relações.

\section{Aspectos metodológicos}

No presente estudo, optou-se por uma abordagem dialética, pois se analisa o processo a partir de suas conexões e contradições, considerando-o como algo em permanente evolução, isto é, não acabado e, em consequência, historicamente modificado. Para Bourguignon (2006), a lógica dialética tem como princípio básico a contradição e negá-la seria "amarrar", "amordaçar" o processo de pensar o real. Como tal, a contradição está no pensamento e na realidade, e, se esta é viva, dinâmica e em movimento, assim também deve ser o pensamento.

A partir dessa perspectiva o trabalho foi realizado utilizando as técnicas de questionário, entrevista e análise documental, amparado na pesquisa bibliográfica, conforme segue:

$\left.1^{\circ}\right)$ análise aos arquivos relacionados ao planejamento, em busca dos elementos que evidenciam a apreensão dos conceitos apresentados na revisão de literatura ora apresentada no cotidiano da discussão do tema em termos regionais. Dessa etapa depreende-se três aspectos básicos, a relação de prioridades regionais com vistas a avançar no seu desenvolvimento, as discussões decorrentes das reuniões realizadas durante 0 processo de elaboração do plano e a compreensão do autor acerca dessas duas abordagens em consonância com a discussão feita posteriormente tanto no âmbito do Conselho quanto na consulta popular.

$2^{\circ}$ ) aplicação dos questionários na Assembleia Regional do Corede realizada em abril de 2011 no município de Saldanha Marinho, com 35 pessoas presentes de um total previsto de 46, representando os 14 municípios da região. Foram respondidas questões sobre a atuação da diretoria do Corede, percepção em torno do desenvolvimento regional e do planejamento, que naquele momento já havia sido publicado e amplamente divulgado inclusive no âmbito do governo do estado e Assembleia Legislativa.

$3^{\text {o) }}$ realização de entrevista semiestruturada com oito membros da Assembleia Regional, presentes em Saldanha Marinho, envolvidos profundamente na discussão durante o processo de planejamento e que tiveram participação ativa nas consultas populares durante o período definido para a análise no presente trabalho, de 2009 a 2012, além de representarem segmentos distintos na composição da população estudada. Os oito entrevistados responderam algumas questões relacionadas aos processos de planejamento estratégico e da consulta popular, bem como sobre o seu envolvimento com o Corede ao longo do tempo.

$\left.4^{\circ}\right)$ consulta ao relatórios e atas relativas à consulta popular nos anos de 2009, 2010, 2011, 2012, para apurar os valores envolvidos e as prioridades eleitas.

5) análise comparativa dos dados quantitativos, estatística descritiva, em consonância com os dados qualitativos, degravação das entrevistas.

Outra importante questão relacionada às técnicas de pesquisa, além das já relatadas, diz respeito à adoção da observação participante, que se deu de forma sistemática em todas as reuniões realizadas pelo Corede Alto Jacuí, nas quais mesmo que informalmente houve a apropriação das informações e da conseqüente trajetória do conselho durante todo o período. 


\section{Discussão e reflexão contextual}

O orçamento do Rio Grande do Sul é regionalizado de acordo com os Coredes, resposta da sociedade e também do governo à Constituição de 1989, e agrupado em nove regiões funcionais. $\mathrm{Na}$ trajetória de mais de 20 anos dos Coredes, houve percalços e avanços, dentre os quais podem ser destacados dois eventos, a criação da consulta popular em 1998 e o financiamento do Governo ao planejamento para o desenvolvimento regional.

Em síntese, a Consulta Popular funciona da seguinte forma: 1) Audiência Pública Regional, na qual se define as diretrizes regionais e as áreas temáticas que serão discutidas no processo; 2) Assembleias Públicas Municipais, nas quais os municípios elencam as suas demandas para encaminhamento ao Fórum Regional e elegem delegados; 3) Fórum Regional onde se define a composição da cédula e se elege os conselheiros para o Fórum Estadual; 4) Votação, com a população escolhendo na cédula de votação as demandas que Ihe convier; e 5) Fórum Estadual, com a homologação dos resultados e encaminhamento do orçamento ao legislativo que corrobora com os itens identificados como oriundos da consulta popular.

Essa é a regra geral de funcionamento, havendo possibilidade de cada Conselho conduzir o processo a seu modo, desde que não desrespeite o básico contido no regimento geral elaborado pelo Governo e pelos Coredes. Ao se associar essa proposição com o apresentado por Teixeira (2002), observa-se que há um hibridismo no processo, pois prevê as duas nuances apresentadas pelo autor sugerindo uma participação orientada para a decisão, quando prevê a realização de uma audiência regional, assembleias municipais e ainda de um fórum regional, cujo funcionamento pressupõe que os presentes possam discutir o que é considerado prioritário para a sua região. Já quando da votação, há a orientação para a expressão, na qual a população em geral tem a possibilidade de exercer mesmo que simbolicamente a forma como gostaria que as autoridades exercessem seus mandatos, concretizados a partir do atendimento de suas demandas locais.

Uma crítica a esse processo, aparecendo inclusive nos depoimentos dos entrevistados é a delimitação apresentada pelo governo no que pode ser encaminhado como prioridade, ou seja, a participação é livre mediante alguns parâmetros previamente estabelecidos. De outro lado, pode-se dizer que o governo não estabelece tais parâmetros como forma de limitar a expressão da cidadania, mas sim orientado pelo constante no Plano Plurianual, o que na prática justifica a limitação em função da legislação vigente, mas "fere" a ideia da democracia subversiva apresentada por Becker (2000).

No entanto, há um ganho nesse processo, segundo Lecours (2002) o institucionalismo sociológico ao enfatizar os aspectos cognitivos acima dos contingenciais reafirma o que o autor chama de construção social, instituições e sociedade são resultado de uma constante troca, perfazendo um ir e vir que molda as suas posturas ao longo do tempo. De forma distinta, Conceição e Nuñez (2007) corroboram a reflexão, ponderando que o recorte regional possibilita distintas formas de articulação assegurando pela participação popular ou cidadã a transversalidade das políticas públicas, que devem resultar em favor da região.

Com relação ao planejamento, foi deliberado pelos Coredes que preferencialmente fosse adotada uma metodologia uniforme entre todos de forma a possibilitar comparações futuras, e elaborados de forma participativa por equipes que convivessem o cotidiano da região, evitando assim contratação de consultorias alheias às particularidades regionais.

Dentre esses conselhos destaca-se no presente trabalho o Corede Alto Jacuí, que possui uma população de 155.264 habitantes, em uma área de 6.905 km2 (IBGE, 2012), distribuídos em 14 municípios: Boa Vista do Cadeado, Boa Vista do Incra, Colorado, Cruz Alta, Fortaleza dos Valos, Ibirubá, Lagoa dos Três Cantos, Não-Me-Toque, Quinze de Novembro, Saldanha Marinho, Salto do Jacuí, Santa Bárbara do Sul, Selbach e Tapera. 
De acordo com o apresentado nas bases conceituais, explica-se a seguir a metodologia utilizada no planejamento para o desenvolvimento regional no Corede Alto Jacuí. Essa baseou-se em técnicas reconhecidas sobre planejamento estratégico, conforme proposição apresentada em Siedenberg e Allebrandt (2010), tendo se distribuído da seguinte forma: 1) diagnóstico técnico, levantamento de dados quantitativos e qualitativos em fontes primárias e secundárias; 2) análise situacional, descrição qualitativa dos dados e informações constantes no diagnóstico técnico, e de apresentação, discussão e validação coletiva e participativa; 3) aplicação da matriz FOFA (Forças, Oportunidades, Fraquezas e Ameaças) regional, visando explicitar potencialidades, desafios, riscos e limitações; 4) referenciais estratégicos, que consistem na explicitação da visão, vocações e valores regionais, utilizados como referência qualitativa no processo de planejamento; 5) proposição de macroobjetivos, desdobrando programas, projetos e ações de desenvolvimento socioeconômico local; 6) estabelecimento de um alinhamento com a Região Funcional de estratégias e programas em comum; e 7) divulgação e implementação do Plano Estratégico de Desenvolvimento Regional, elaborado de forma integrada e participativa.

Como pano de fundo levou-se em consideração, também, uma colocação feita por Boisier (1995, p.47-8):

La planificación del desarollo regional es, primero que todo, una actividad societal, em el sentido de ser una responsabilidad compartida por varios actores sociales: El Estado desde luego, por varias y la propia Región, em cuanto comunidad regional, polifacetica, contradictoria y difusa a veces, pero comunidad al fin, locacionalmente específica y diferenciada. Sin la participación regional solo consiste - como por lo demás prueba la experiencia histórica - en un procedimiento de arriba hacia abajo para asignar recursos financieros o de otra índole entre espacios arbitraria o erróneamente llamados "regiones".

Dessa forma, é necessário frisar que a metodologia adotada no processo de planejamento intencionou contar com ampla participação dos cidadãos, das instituições públicas e privadas que atuam na região, viabilizadas por meio de assembleias ou audiências públicas, fomentando o exercício da cidadania nas diferentes etapas, embora a mesma tenha ficado aquém da expectativa tanto da diretoria do conselho quanto da equipe de profissionais envolvidos na atividade.

Primeiramente, houve uma reunião da equipe técnica com a assembléia regional do Corede com a apresentação da metodologia e o diagnóstico quantitativo. Em seguida, foram realizadas reuniões nos municípios com a apresentação do diagnostico quantitativo e o início do diagnóstico qualitativo, elaborado a partir da contribuição de cada assembleia municipal. Na sequência, a região foi subdividida em três microrregiões por aproximação geográfica e da matriz produtiva, tendo se realizado diversas reuniões em caráter de assembléia e oficinas para a construção do plano propriamente dito, que foi encerrado em uma nova assembléia regional para elaboração e aprovação da carteira de projetos. A partir do plano seria desejável que o mesmo passasse a nortear as discussões regionais com vistas a suprir as lacunas ou mesmo avançar no alcance dos objetivos da região no sentido do seu desenvolvimento. (CORRÊA et al, 2010)

Dando prosseguimento ao propósito do trabalho, passa-se a discutir a partir de agora as interfaces entre planejamento e consulta popular, levando em consideração as noções sobre desenvolvimento apresentadas pela assembleia regional do Corede. Recuperando a afirmação de Becker (2003), o desenvolvimento deve ser resultado de um conjunto de estratégias articuladas e implementadas pelos agentes regionais. Dessa forma, com vistas a compreender a percepção de desenvolvimento e do papel do Corede para a assembleia regional e da forma como a mesma é contemplada nas discussões do planejamento e na consulta popular.

Com relação à noção de desenvolvimento, observou-se que para $81 \%$ dos entrevistados desenvolvimento é sinônimo de geração de renda, levando a interpretação de que o foco das ações do 
Corede deva ser na ampliação da renda. A avaliação é de que a região apresenta uma condição de desenvolvimento boa, 65\% e nenhuma indicação de excelente, contrapondo a avaliação da Fundação de Economia e Estatística (FEE, 2013) que apresenta o Alto Jacuí com alto grau de desenvolvimento, equivalente à excelente. Outra observação feita é a de que para $46 \%$ das indicações um dos principais gargalos da região é a questão do saneamento básico, que de certa forma coaduna a noção de bom desenvolvimento "apenas", embora fique uma interrogação quanto ao alto nível de renda da região.

A mesma assembleia identifica e reconhece como principais funções do Corede "a promoção do desenvolvimento harmônico e sustentável”, com $81 \%$ das indicações, e com $77 \%$ das indicações a "elaboração de planos estratégicos de desenvolvimento regional". Observa-se nesse caso uma contradição, pois o entendimento de que o desenvolvimento é principalmente associado à geração de renda vai de encontro à noção de "harmônico e sustentável" que remetem ao equilíbrio na distribuição da riqueza e das oportunidades e também aos aspectos de preservação ambiental, conforme o preceituado por Costa e Cunha (2002). Já com relação ao planejamento há coerência nos significados apontados nos questionários, conforme demonstrado nos escritos de vários autores, (BUARQUE, 1999; OLIVEIRA E LIMA, 2003; BECKER, 2003; SIEDENBERG E ALLEBRANDT, 2010).

Quanto a atuação do Corede, 85\% dos integrantes da Assembleia Regional entendem ser o Corede um estimulador das discussões em torno das políticas de desenvolvimento da região e o faz auxiliado pelos Comudes (Conselhos Municipais de Desenvolvimento). Mais uma vez retoma-se Becker (2003), com relação à referência de que as articulações regionais podem efetivamente contribuir para o desenvolvimento regional. Pode-se afirmar ainda que essa articulação indicada pela assembleia entre Corede e Comudes contribui também para a qualificação da participação conforme preceituado por Buarque (1999), Becker (2003), Oliveira e Lima
(2003), Siedenberg; Allebrandt (2010), que associam a necessidade de um planejamento com 0 envolvimento dos atores, ou seja, a participação da região. Corroborando com isso, a própria Assembleia, segundo $89 \%$ dos seus membros acredita que o Corede exerce influência frente às organizações públicas e privadas atuantes na região.

Questionados quanto à expectativa em relação ao planejamento, $65 \%$ dos entrevistados a classificaram como boa, no entanto 96\% acreditam que o planejamento trará mudanças benéficas para região. Constata-se aqui uma contradição, pois a expectativa com relação ao plano é bem menor do que a opinião de que o mesmo trará benefícios à região, quando na verdade as duas respostas deveriam convergir. Com base no apontado por Lecours (2002) sendo a região resultado de suas instituições, e se essas se articulam em prol da mesma, natural seria a convergência de opiniões, o que não se verifica.

Mais algumas contradições foram evidenciadas no cruzamento dos questionários com as entrevista, que foi feita com membros da Assembleia e participantes do planejamento. Foram entrevistadas oito pessoas: um vice-prefeito, três secretários municipais, um vereador e três integrantes de Comude, sendo que dois deles foram integrantes da Diretoria do Corede. Além disso, quatro dos entrevistados são funcionários públicos municipais de carreira, um deles é funcionário público estadual e os outros três são profissionais liberais. Cinco desses são filiados a partidos políticos e os outros três não são militantes partidários.

Todos os entrevistados entendem que 0 trabalho realizado pelo Corede vem melhorando com - passar do tempo, sobretudo nas questões procedimentais, em que pese eventuais deficiências estruturais. Importante salientar as dificuldades enfrentadas na manutenção do trabalho do Corede em função da crise política e financeira enfrentada pela Universidade de Cruz Alta (Unicruz) a partir de 2005, o que fragilizou a estrutura disponibilizada para o Conselho. Desde a criação do Corede a Unicruz participa da diretoria do mesmo assumindo um papel 
de apoio técnico, além de alguns cargos que eventualmente também tenham sido ocupados por seus indicados.

A crise de 2005 obrigou a universidade a se reestruturar e em consequência diminuir a estrutura disponibilizada, o que fragilizou o trabalho do Conselho. Como efeito disso a atuação da diretoria se precarizou comprometendo o funcionamento, pois não possuía sequer as certidões de regularidade fiscal. A partir do final de 2008 a Unicruz reassume a secretaria executiva do Conselho iniciando um trabalho de recuperação da estrutura funcional do conselho bem como da retomada das discussões. É nesse contexto que os entrevistados se situam, atribuindo então a melhora na atuação do Corede, entendido como sinônimo de sua diretoria, em comparação ao momento anterior. A melhoria é observada especialmente nos procedimentos operacionais, com um processo lento, mas constante de maior clareza e transparência nas informações e discussões, o que como resultado imediato é percebido a maior qualificação nas discussões. Embora as mesmas ainda encontrem-se num patamar distante do mensurado por Teixeira (2002), que pressupõe que a participação não seja um evento episódico e sim permanente e contraditório, envolvendo interesses e valores diferenciados dos atores, o que requer conforme Becker (2003), uma democracia mais subversiva, com maior comprometimento dos envolvidos. No entanto, essa melhora na forma de atuação do Corede tem possibilitado que a sociedade entenda melhor 0 processo, sendo ainda necessário aprofundar uma maior apropriação do real significado do que é participação.

Os entrevistados consideram a Consulta Popular uma importante forma de participação, sendo vista como contraponto ao sistema de emendas parlamentares. Mesmo reconhecendo a dificuldade imposta pelo método, o ganho principal é esse, canal de manifestação, o que Lecours (2002) chama de aspectos cognitivos. Reconhecem que mesmo havendo muito a melhorar, sobretudo na conscientização da população em geral, o processo vem evoluindo ao evidenciar uma apropriação maior dos envolvidos, verificando-se também mais transparência na condução da discussão. Dentre os problemas, são citados as questões relacionadas à forma como se constituem os grupos de discussão que são ainda integrados por poucos que acabam "dominando" e centralizando em si o processo, com vistas a garantir a satisfação dos seus interesses, que normalmente são em favor de uma estrutura do estado.

Uma situação posta em discussão na presente reflexão é a interação das prioridades escolhidas na consulta popular com o apontado no planejamento. Durante o planejamento e também nos questionários respondidos pela Assembleia Regional as chamadas áreas básicas de atuação do Estado (educação, saúde e segurança) não foram apontadas como prioritárias. Mas essas áreas sempre aparecem na Consulta Popular, no entanto há algumas divergências entre os entrevistados na explicação para tal fato, mas a principal é a omissão dessas áreas no planejamento, mesmo que por motivos distintos.

Nas discussões do Corede, tanto da assembleia quanto da diretoria, é quase consensual, poucas manifestações contrárias, que tais áreas são função básica do Estado, e que incluí-las na discussão significaria "liberá-lo" de suas obrigações primeiras. Tais áreas são chamadas de básicas justamente porque devem ser preocupação dos agentes públicos de forma prioritária, e consequentemente não deveriam ser sequer postas em discussão. Deriva desse raciocínio a argumentação dos integrantes do Corede com relação às áreas básicas, pois como tal não cabe o questionamento quanto a ser prioridade ou não, sendo óbvia então a sua priorização sem consulta. Essa é uma grande contradição do processo, pois os mesmos que ponderam sobre ser condição necessária e de pura responsabilidade do Estado, quando se fala nessas áreas, são os mesmos que as defendem na Consulta Popular do Corede Alto Jacuí. Em sua defesa argumentam tal medida se deve em 
função do relativo abandono dessas áreas pelos sucessivos governos ao longo do tempo.

Dos oito entrevistados, apenas dois admitem que as três áreas básicas devam fazer parte da discussão e consequentemente receberem recursos em condições de igualdade às demais áreas que eventualmente estejam em discussão. Outros três consideram que tais áreas não deveriam fazer parte da discussão, por já haver vinculação orçamentária para a educação e a saúde, e que segurança é uma das funções originais do Estado. Os outros três entrevistados discordam também, mas se resignam com as condições precárias de funcionamento dessas estruturas, tornando-se compreensível, em sua opinião, que se mobilizem para pleitear recursos. É unanimidade entre os entrevistados que essas áreas são tão essenciais, que perguntar se são prioridades chega ser irônico, pois na prática significa perguntar à população se o Estado deveria cumprir os preceitos constitucionais, como é o caso das vinculações orçamentárias. Embora todos sejam compreensivos com as condições de trabalho, e as consequentes limitações em atender as demandas da população, os entrevistados não poupam críticas à posição assumidas pelas áreas.

Pode-se afirmar que há consenso entre os entrevistados quando questionados a respeito da relação entre o planejamento e a Consulta Popular, com todos afirmando que um subsidia as discussões do outro, embora com algumas ressalvas. Dentre as ressalvas relacionam-se as diretrizes apresentadas pelo Estado como base da discussão na Consulta Popular, a burocracia envolvendo o encaminhamento dos projetos elencados e a falta de apropriação pela população da ferramenta disponibilizada, o planejamento, gerando com isso a movimentação das estruturas das áreas básicas na busca dos recursos, normalmente exitosa.

A síntese do processo é que, de um lado o governo conclama à participação, e divulga isso como conquista da população, que por sua vez tem uma visão relativamente estreita do processo (alheia aos aspectos legais e factuais da elaboração do orçamento que deve ser apresentado às esferas competentes), de outro dificulta o processo de discussão da população a aspectos bem pontuais que não atendem de forma consistente os anseios da mesma.

Reflexão feita por Büttenbender; Siedenberg; Allebrandt (2011, p.12), explicita bem tal situação.

Representantes de interesses corporativos que descobriram o canal da Consulta Popular para encaminhar projetos de desenvolvimento - cuja execução tem maior garantia do que a própria previsão orçamentária - procuram garantir a inclusão de temáticas e ações que contemplem a Saúde, a Educação e a Segurança Pública no processo que deveria priorizar ações e/ou projetos estruturantes que tenham um reflexo efetivo no desenvolvimento de cada região.

Além disso, também é necessário mencionar que 0 achismo das lideranças sobre quais ações e projetos efetivamente tem condições de desencadear o desenvolvimento regional muitas vezes se contrapõe aos estudos técnicos e contribui de maneira significativa para que o processo de escolha de projetos estruturantes apresente poucos resultados concretos.

Ainda assim, a ferramenta é reconhecida como relevante e subsidia a discussão, a elaboração de planos de governo, reflete a discussão na região e se revela pedagógica ao processo de participação. Ficam latentes aqui as contradições envolvidas, embora admitam que a consulta devesse ser uma fonte de financiamento ao planejamento, sucumbem às pressões durante 0 processo. De forma pragmática, os atores optam pela via de melhor resistência, caso contrário o governo deveria ser pressionado a atender as áreas básicas e questionar a população sobre em quais outras áreas investir para atender suas expectativas. Fica muito mais fácil apoiar as grandes estruturas do que abrir uma discussão que fatalmente vai gerar conflito de interesses culminando em um embate que ao que tudo indica não interessa aos condutores do processo. Conflito esse reconhecido pela assembleia regional ao apontar que é necessário superar os problemas relacionados ao saneamento, em contraponto entende que o desenvolvimento é sinônimo de renda e opta por encaminhar apoio à segurança pública, por exemplo. O que ainda mais 
evidente fica, quando se cruza os dois processos, planejamento e consulta popular.

No planejamento, foram sistematizados 22 projetos, dos quais após uma depuração das possibilidades de viabilização e também de equiparação com as diretrizes para a consulta popular são sintetizados na seguinte lista elaborada com base nas demandas ao longo do período analisado: 1) agricultura, posteriormente substituída por desenvolvimento rural; 2) desenvolvimento econômico; 3) segurança; 4) educação; 5) saúde; 6) justiça e cidadania; 7) habitação, saneamento e meio ambiente; 8) turismo; 9) esportes e 10) infraestrutura,

Durante os quatro anos analisados foram discutidos e aprovados pela consulta popular 229 projetos, dos quais 134 foram para as áreas básicas, o que equivale a $59 \%$ do total, restando, portanto $41 \%$ ou 95 para as áreas priorizadas pelo planejamento. Dos 134 projetos das áreas básicas, 57 foram destinados à segurança, ou seja, 43\%. Já dos 95 das áreas priorizadas, 57\%, foram relacionados ao desenvolvimento rural.

Tabela 1 - Número de projetos aprovados na Consulta Popular entre 2009 e 2012

\begin{tabular}{l|r|r|r|r}
\hline \multicolumn{1}{c|}{ ÁREA } & $\mathbf{2 0 0 9}$ & $\mathbf{2 0 1 0}$ & $\mathbf{2 0 1 1}$ & $\mathbf{2 0 1 2}$ \\
\hline Saúde & 7 & 10 & 11 & 6 \\
Segurança & 14 & 14 & 17 & 12 \\
Educação & 10 & 11 & 9 & 14 \\
Agricultura / & & & & \\
Desenvolvimento & 16 & 15 & 15 & 8 \\
Rural & 3 & - & 1 & 6 \\
Turismo & - & - & - & 2 \\
Desenvolvimento & & & & \\
Econômico & & & & \\
Habitação, & 1 & 1 & 5 & 4 \\
Saneamento e Meio & 1 & - & - & - \\
Ambiente & 2 & - & - & 3 \\
Justiça e Cidadania & 58 & 56 & 60 & 55 \\
Infraestrutura & & & \\
Esportes & &
\end{tabular}

Fonte: Elaboração do autor com base nos relatórios da Consulta Popular.

Quando se considera os valores envolvidos nos projetos, as áreas básicas foram contempladas com 5,9 milhões, o que equivale a $56 \%$ do total, restando, portanto $44 \%$, ou 4,6 milhões para as áreas priorizadas pelo planejamento. Do total das áreas básicas, 48\% foram destinados à segurança, ou seja, 2,8 milhões. Já no caso das áreas priorizadas, 62\%, foram relacionados ao desenvolvimento rural. Em parte, há coerência com os valores discutidos para as áreas priorizadas e o argumento de que a agricultura deveria ser a área prioritária a ser atendida pela Consulta Popular, apontada de forma unânime pelos entrevistados. Apenas aparecendo controvérsia com relação às áreas básicas, pois há uma resistência importante no discurso, mas que não se verifica na prática.

Tabela 2 - Valores dos projetos aprovados na Consulta Popular entre 2009 e 2012

\begin{tabular}{|c|c|c|c|c|}
\hline ÁREA & 2009 & 2010 & 2011 & 2012 \\
\hline \multirow[t]{2}{*}{ Saúde } & $\begin{array}{r}339.800 \\
00\end{array}$ & $\begin{array}{r}398.000, \\
00\end{array}$ & $\begin{array}{r}624.335 \\
99\end{array}$ & $\begin{array}{r}446.831 \\
99\end{array}$ \\
\hline & 355.000, & 731.000, & 694.000, & 1.040 .00 \\
\hline Segurança & & & & 0,00 \\
\hline Educação & $\begin{array}{r}230.000 \\
00\end{array}$ & $\begin{array}{r}280.240 \\
00\end{array}$ & $\begin{array}{r}417.296 \\
00\end{array}$ & $\begin{array}{r}357.000 \\
00\end{array}$ \\
\hline Agricultura / & 734.000, & 991.051, & 752.200, & 375.000, \\
\hline $\begin{array}{l}\text { mento Rural } \\
\text { Desenvolvi } \\
\text { mento } \\
\text { Econômico }\end{array}$ & 00 & 90 & 00 & $\begin{array}{r}00 \\
110.000 \\
00\end{array}$ \\
\hline Turismo & $\begin{array}{r}18.800,0 \\
0\end{array}$ & & & $\begin{array}{r}270.000 \\
00\end{array}$ \\
\hline $\begin{array}{l}\text { Habitação, } \\
\text { Saneament } \\
\text { o e Meio } \\
\text { Ambiente }\end{array}$ & $\begin{array}{r}176.000 \\
00\end{array}$ & $\begin{array}{r}415.000 \\
00\end{array}$ & $\begin{array}{r}70.000,0 \\
0\end{array}$ & $\begin{array}{r}171.000 \\
00\end{array}$ \\
\hline Justiça e & $19.750,0$ & $20.540,0$ & 258.000, & \\
\hline Cidadania & & 0 & & \\
\hline $\begin{array}{l}\text { Infraestrutur } \\
\text { a }\end{array}$ & $\begin{array}{r}100.000 \\
00\end{array}$ & & & \\
\hline & $26.584,0$ & & $20.000,0$ & $66.000,0$ \\
\hline Esportes & $\begin{array}{r}0 \\
1.999 .93\end{array}$ & 2.835 .83 & $\begin{array}{r}0 \\
2.835 .83\end{array}$ & $\begin{array}{r}0 \\
2.835 .83\end{array}$ \\
\hline Total Geral & 4,00 & 1,90 & 1,99 & 1,99 \\
\hline
\end{tabular}

Fonte: Elaboração do autor com base nos relatórios da Consulta Popular.

O resultado dos depoimentos colhidos remete a uma avaliação de que falta avançar em termos estratégicos na região, ou seja, suas lideranças, ou parte delas, ainda estão muito focadas em questões 
de cunho mais cotidiano, o que impossibilita uma visão de longo prazo. Essa limitação, somada à postura reivindicatória das estruturas básicas do Estado, acaba restringindo e impedindo a qualificação da participação da cidadania nas discussões.

Resgata-se nesse momento a base conceitual adotada, entendendo que as questões inerentes ao desenvolvimento regional são decorrentes de um processo de longo prazo, e, portanto, condicionadas à continuidade, por isso a necessidade de se ter um planejamento. Entendendo também que 0 planejamento requer um processo participativo, e que a participação será tão qualificada quanto for a conformação institucional dessa sociedade. Dessa forma, como base do processo, denota-se que no caso específico do Corede Alto Jacuí e, de maneira geral no Estado do Rio Grande do Sul, há ainda um longo caminho a ser trilhado para se atingir um grau de amadurecimento compatível com o preconizado pela literatura.

\section{Considerações finais}

Ao longo dos mais de 20 anos de trajetória dos Coredes, os mesmos têm exercido alguns papéis de relevância na trajetória do Estado, sobretudo no que diz respeito aos processos participativos. Cita-se como exemplo, a Consulta Popular, que, desde 1998, é realizada no Estado com parceria entre o Governo e os Corede. Outro exemplo da atuação desses conselhos foi o Planejamento do Desenvolvimento Regional, financiado pelo Governo.

Justamente esse foi o escopo da discussão proposta no trabalho, analisar a relação existente entre o que foi discutido como prioritário para a região durante o planejamento e o que foi deliberado no processo de consulta à população em confronto com o manifestado pela Assembleia Regional; assumindo como pressuposto básico, de que os recursos da consulta popular poderiam financiar alguns dos projetos elencados como prioritários no planejamento.

Ao se discutir a Consulta Popular na região, foi feita a distinção entre as áreas básicas, composta por educação, saúde e segurança; e prioritárias, composta pelas áreas indicadas no planejamento, desenvolvimento rural (agricultura), turismo, saneamento, desenvolvimento econômico, justiça e cidadania e infraestrutura. Em observação pormenorizada, fica evidenciado que, das áreas prioritárias a mais lembrada é o desenvolvimento rural, já as áreas básicas são bastante contempladas sempre, com $56 \%$ dos recursos ao longo do período. No entanto os questionários sinalizam que o saneamento básico seria o principal gargalo da região, área essa que foi pouco priorizada durante o período.

Outra questão que se observa é que as áreas recebem mais recursos, são as que têm suas estruturas envolvidas nas articulações, o que explica em parte 0 alto percentual recebido pelas áreas básicas, pois as mesmas são representadas pelas maiores estruturas instaladas nos municípios. O que também é corroborado pelo apelo das mesmas junto à população. Outra observação que se faz é que a opção pela via de menor resistência nas articulações regionais também fortalece tais pleitos restando às municipalidades de forma individual ou através da interferência parlamentar buscar o enfrentamento dos problemas de saneamento.

Depreende-se então, que o Planejamento não serve de base para a discussão, pelo menos não como deveria. Os conceitos utilizados pressupõem que o planejamento é racional, mas não foi o observado, mesmo que os entrevistados tenham afirmado tal condição. Os aspectos institucionais, apostos como de caráter mais pragmático, prevaleceram nesse caso, relegando ao plano um papel acessório, e não central no processo. De outro lado os projetos apontados pelo planejamento integram o Plano Plurianual elaborado pelo governo do Estado, o que possibilita indiretamente com que o mesmo venha a ser atendido, mediante outras formas de articulação. Nesse aspecto a questão institucional "colabora" com a viabilização do plano, pois nesta esfera os Coredes de maneira geral acabam fazendo o que fazem as estruturas do Estado nas regiões, inclusive como apontado nos questionários da Assembleia, os mesmos podem "interferir nas ações 
das organizações públicas e privadas da região" e até do Estado.

Os entrevistados apontam que há problemas na atuação do Corede, mas que desde a sua reestruturação, a situação vem se encaminhando para superação dos mesmos. Tais problemas remetem ao baixo nível de participação, que, embora reconhecida como qualificada, ainda é limitada a grupos de interesse bem específicos, remetendo a crítica à democracia participada, na qual a participação é conduzida pela coordenação do processo, enquanto que o desejado é a democracia participante, que pressupõe autonomia aos cidadãos, o que parece não se verificar neste caso. Segundo vários depoimentos, o agente público coage a comunidade a priorizar a demanda de sua estrutura sob pena de abandono a ação do Estado nessa particularidade. Com isso, a autoridade legitima seu pleito individual como se coletivo fosse. Mesmo que eventualmente coincida com a vontade da população, a crítica remete à manobra feita para validar a demanda independente do seu mérito, que muito provavelmente exista.

Isso demonstra toda a contradição inerente ao processo, na qual o cidadão reconhece a importância da demanda, mas acha que, como a mesma é obrigação do Estado, nem deveria ser posta em discussão. Ao mesmo tempo o próprio Estado, por meio da estrutura em questão, constrange o cidadão a elencar sua demanda e usa o processo de participação para legitimar sua obrigação, como se esse o fosse resultado da vontade popular.

De outro lado, os munícipes se debatem em discussão sobre o que entendem mais importante, se atender ao "povo" de forma mais coletiva, contemplando as áreas básicas, ou atendendo alguns em particular (agricultura, por exemplo), enfrentando aí um dilema. Surge a dicotomia do coletivo versus o particular, e acaba normalmente prevalecendo o maior poder de mobilização, independente do resultado que isso possa gerar.

Como conclusão derradeira deste estudo, pode-se colocar que ainda há um longo caminho a ser percorrido quando se pensa em participação popular no Rio Grande do Sul, de maneira geral, e no Corede Alto Jacuí, em particular. É necessário que se supere questões relacionadas à apropriação por parte da cidadania para que efetivamente esta se apodere do processo. Há ainda que se superar questões de cunho ideológico, para que haja uma maior identificação com os projetos regionais e não com projetos partidários ou pessoais. Falta, ainda, uma maior clareza em torno do que efetivamente é "participação", de forma que isto contribua para que se supere a cultura da decisão isolada e "salvadora" dos agentes públicos.

\section{Referências}

BECKER, D. F. REDENEP: a pesquisa, o planejamento e a gestão do desenvolvimento localregional. Lajeado: UNIVATES, 2000.

A economia política do (des)envolvimento regional contemporâneo. IN: BECKER, D. F. \& WITTMANN, M. (Orgs.). Desenvolvimento regional: abordagens interdisciplinares. Santa Cruz do Sul: EdUNISC, 2003.

BOISIER, S. Centralización y descentralización territorial en el proceso decisorio del sector publico. Santiago de Chile: ILPES/CEPAL, 1995.

BOURGUIGNON, J. A. Processo da pesquisa e suas implicações teórico-metodológicas e sociais. Emancipação, v.6, n.1, p. 41-52, 2006.

BUARQUE, S. C. Metodologia de planejamento do desenvolvimento local e municipal sustentável. Brasília: INCRA/IICA, 1999.

BÜTTENBENDER, P. L.; SIEDENBERG, D. R.; ALLEBRANDT, S. L. Coredes: estruturação, articulações intra e inter-regionais, referenciais estratégicos e considerações críticas. In: DALLABRIDA, V. R. (org.). Governança territorial e desenvolvimento: descentralização políticoadministrativa, estrutura subnacionais de gestão do desenvolvimento e capacidades estatais. Rio de Janeiro: Garamond, 2011. p. 311-338.

CONCEIÇÃO R. J. da \& NUÑEZ B. E. C. Planejamento participativo e desenvolvimento regional sustentável: uma análise do método aplicado na Região Metropolitana de Curitiba (RMC). Seminário Nacional "Paisagem e Participação": práticas no espaço livre público São Paulo, 2007. Disponível em <http://www.fau.usp.br/eventos/paisagemeparticipaca o/poderpublico/A03_pd_rmc.pdf> Acesso em: 02 nov. 2011. 
CORRÊA, J. C. S. O plano estratégico de desenvolvimento regional e suas interfaces com a consulta popular no Corede Alto Jacuí, no período de 2009 a 2012. 136 f. Dissertação (Programa de PósGraduação em Desenvolvimento Regional - Mestrado e Doutorado). Universidade de Santa Cruz do Sul, Santa Cruz do Sul, outubro de 2013.

CORRÊA, J. C. S.; et. al. Planejamento estratégico de desenvolvimento regional: Conselho Regional de Desenvolvimento Alto Jacuí. Cruz Alta: UNICRUZ, 2010.

CostA, F. L. da; CUNHA, A. P. G. Pensar o desenvolvimento a partir do local: novo desafio para os gestores públicos. VII Congreso Internacional del CLAD sobre la Reforma del Estado y de la Administración Pública, Anais... Lisboa, Portugal, 811, Oct. 2002.

FEE. Fundação de Economia e Estatística. IDESE. Disponível em <http://www.fee.rs.gov.br/indicadores/indice-dedesenvolvimento-socioeconomico/> Acesso em Nov. 2013.

IBGE. 2012. Cidades@. Disponível em $<$ http://cidades.ibge.gov.br/xtras/uf.php?lang=\&coduf= 43\&search=rio-grande-do-sul>. Acesso em 15 set. 2014.

LECOURS, A. L'approche néo-institutionnaliste en science politique. Politique et Sociétés, Société québécoise de science politique, Quebec, v. 21, n. 3, 2002.

LIMA, A. C. C.; SIMÕES, R. F. Teorias do desenvolvimento regional e suas implicações de política econômica no pós-guerra: o caso do Brasil. Texto para discussão no 358. Belo Horizonte: UFMG/Cedeplar, 2009. Disponível em: <http://www.cedeplar.ufmg.br/pesquisas/td/TD\%2035 8.pdf>. Acesso em: 21 abr. 2013.

LIMA, L. G. A perspectiva do desenvolvimento regional no Corede Alto Jacuí. Monografia de Graduação (Curso de Ciências Econômicas) Universidade de Cruz Alta, Cruz Alta, julho de 2011.

LOPES, P. Participação das populações locais no desenvolvimento da educação. Caso de estudo: escolas comunitárias da região de Batafá, GuinéBissau, 2004-2006. Dissertação de Mestrado Instituto Superior de Ciências do Trabalho e da Empresa, 2008.

NALLE JUNIOR, C. Desenvolvimento regional e políticas públicas: o caso do Projeto Amanhã da Companhia de Desenvolvimento dos Vales do São Francisco e Parnaíba. Dissertação de Mestrado (Programa de Pós-Graduação em Administração de Organizações) - Universidade de São Paulo, Ribeirão Preto, 2006.

OLIVEIRA, G. B. de \& LIMA, J. E. de S. Elementos endógenos do desenvolvimento regional: consideracões sobre o papel da sociedade local no processo de desenvolvimento sustentável. Rev. FAE, Curitiba, v.6, n.2, p.29-37, maio/dez. 2003.

RAMOS, M. P.; MARINO, J. M. F. Condicionantes históricos o desenvolvimento capitalista global em nível regional. In: WITTMANN, M. L.; RAMOS, M. P. Desenvolvimento regional: capital social, redes e planejamento. Santa Cruz do Sul: Edunisc, 2004.

RIO GRANDE DO SUL. Lei n. 10.283, de 17 de outubro de 1994. Disponível em: <http://www.al.rs.gov.br/legis/M010/M0100018.asp?Hi d_IdNorma=12666\&Texto=> Acesso em: 22 jul. 2011.

SEN, A. K. Desenvolvimento como liberdade. São Paulo: Companhia das Letras, 2000.

SIEDENBERG, D. R.; ALLEBRANDT, S. L. Fundamentos do planejamento. IN: SIEDENBERG, D. R. (Org.). Fundamentos e técnicas de planejamento estratégico local/regional. Santa Cruz do Sul: Edunisc: 2010. p. 29-48.

SIEDENBERG, D. R. Um modelo aplicado: o planejamento nos Coredes. In: SIEDENBERG, D. R. (Org.). Fundamentos e técnicas de planejamento estratégico local/regional. Santa Cruz do Sul: Edunisc: 2010. p. 87-98

SIEDENBERG, D. R.; SAAD, A. Z.; SENGER, M. S. Bases do planejamento e estratégias do desenvolvimento regional no RS. In: II Seminário Internacional sobre Desenvolvimento Regional. Anais. Santa Cruz do Sul, RS - Brasil - 28 set. a 01 de out. $2004 . \quad$ Disponível em: <http://www.unisc.br/site/sidr/2004/planejamento/10.p df>. Acesso em 01 nov. 2015.

TEIXEIRA, E. C. O local e o global: limites e desafios da participação cidadã. 3. ed. São Paulo: Cortez; Recife: Equip; Salvador: UFBA, 2002.

UGARTE, P. S. Que participação para qual democracia. In: COELHO, V. S. P. e NOBRE, M. (org.) Participação e deliberação: teoria democrática e experiências institucionais no Brasil contemporâneo. São Paulo: 34, 2004. p. 93-106. 